\title{
Pathfinding by Identified Zebrafish Motoneurons in the Absence of Muscle Pioneers
}

\author{
Ellie Melançon, ${ }^{1}$ Dennis W. C. Liu, ${ }^{2}$ Monte Westerfield, ${ }^{1}$ and Judith S. Eisen ${ }^{1}$ \\ 1/nstitute of Neuroscience, University of Oregon, Eugene, Oregon 97403-1254, and ${ }^{2 H o w a r d ~ H u g h e s ~ M e d i c a l ~ I n s t i t u t e, ~}$ \\ Chevy Chase, Maryland 20815-6789
}

\begin{abstract}
To identify the cellular cues that guide zebrafish neuronal growth cones to their targets, we examined interactions between identified motor growth cones and identified muscle fibers and tested whether these fibers were required for growth cone navigation. Caudal primary motoneurons (CaPs) and middle primary motoneurons (MiPs) are identified motoneurons that innervate cell-specific regions of the myotome. Growth cones of both cells initially extend along a common pathway and then pause at a set of identified muscle fibers, called muscle pioneers, before diverging along cell-specific pathways. Muscle pioneers are intermediate targets of both $\mathrm{CaP}$ and MiP (Westerfield et al., 1986; Liu and Westerfield, 1990); both motoneurons extend their growth cones directly to the muscle pioneers on which the first functional neuromuscular contacts form, suggesting that muscle pioneers may provide guidance information to these growth cones. We tested this idea by
\end{abstract}

ablating muscle pioneers and observing the resulting motor axonal trajectories. Both $\mathrm{CaP}$ and MiP ultimately formed normal axonal arbors after muscle pioneer ablation, showing that muscle pioneers are unnecessary for formation of correct axonal trajectories; however, although final cellular morphology was correct in the absence of muscle pioneers, MiP growth cones branched abnormally or extended ventrally beyond the common pathway. Ablation of $\mathrm{CaP}$ and the muscle pioneers together increased the aberrant behavior of the MiP growth cone. Our results provide evidence that an intermediate target, the muscle pioneers, affects motor axonal extension without altering target choice, suggesting that other cues also contribute to proper pathway navigation.

Key words: acetylcholine receptors; neuromuscular junctions; axogenesis; zebrafish motoneurons; muscle pioneers; pathway navigation
The environment through which growth cones navigate contains cues that regulate neuronal pathfinding (Frank and Wenner, 1993; Goodman and Shatz, 1993; Keynes and Cook, 1995). En route to their synaptic targets, neurons may project axons to intermediate targets that influence subsequent pathway choice (Dodd et al., 1988). For example, some grasshopper pioneer neurons project to guidepost cells (Bentley and Keshishian, 1982) that are required for normal pathfinding (Bentley and Caudy, 1983). Chick hindlimb motoneurons (Lance-Jones and Landmesser, 1981; Tosney and Landmesser, 1985a,b; Landmesser, 1992) and spinal commissural neurons (Bovolenta and Dodd, 1991) also project to specific intermediate targets, which appear to influence extension. These results suggest that intermediate targets serve as choice points for pathway selection.

We examined the role of potential intermediate targets in the pathway choices of zebrafish primary motoneurons. We focused on the first two primary motoneurons to extend growth cones out of the spinal cord: CaP and MiP (see Fig. 1) (Eisen et al., 1986; Myers et al., 1986). The CaP growth cone pioneers a common pathway to the nascent horizontal myoseptum, where it pauses before selecting its cell-specific pathway along ventral myotome

Received March 24, 1997; revised July 28, 1997; accepted July 30, 1997.

This work was funded by National Institutes of Health Grants NS23915, NS21132, and HD22486. We thank Susan Pike and Bettina Debu for contributing to early aspects of this work; Michael Bate, Christine Beattie, Charles Kimmel, Beth Morin-Kensicki, John H. Postlethwait, David Raible, and Kathleen Whitlock for suggestions on this manuscript; Ruth Bremiller for histology advice; Eric Schabtach for help with electron microscopy; Jerry Gleason for photography assistance; and the University of Oregon Zebrafish Facility staff for fish care.

Correspondence should be addressed to Ellie Melançon, Institute of Neuroscience, University of Oregon, Eugene, OR 97403-1254.

Copyright (C) 1997 Society for Neuroscience $0270-6474 / 97 / 177796-09 \$ 05.00 / 0$
(Eisen et al., 1986; Myers et al., 1986). The MiP growth cone extends along the common pathway, pausing at the distal end of this pathway before sprouting a collateral that extends along dorsal myotome; the original ventral axon is later retracted. Interactions among primary motoneurons seem unnecessary for proper pathway selection (Eisen et al., 1989; Pike and Eisen, 1990), and primary motoneurons seem not to compete for targets (Liu and Westerfield, 1990). Thus, the region where motor growth cones pause might contain signals necessary for appropriate cell-specific pathway selection.

Identified muscle cells called muscle pioneers (Felsenfeld et al., 1991) are candidate intermediate targets that influence primary motor growth cone pathway choice. Located at the distal end of the common pathway and defining the nascent horizontal myoseptum, muscle pioneers are distinguishable from other somitic cells as the first to express muscle-specific characteristics (Waterman, 1969; van Raamsdonk et al., 1974; Myers et al., 1986; Felsenfeld et al., 1991; Hatta et al., 1991a) and assemble elements necessary for functional neuromuscular activity (Myers et al., 1986; Hanneman and Westerfield, 1989; Liu and Westerfield, 1990, 1992). Zebrafish muscle pioneers fulfill criteria distinguishing guidepost cells in grasshoppers (for review, see Jellies, 1990; Palka et al., 1992) and intermediate targets in the rat CNS (Bovolenta and Dodd, 1990), mouse optic chiasm (Sretavan et al., 1995), and chick hindlimb plexus (Lance-Jones and Dias, 1991). Thus, muscle pioneers may provide signals important for motoneuronal pathway choice.

We asked whether $\mathrm{CaP}$ and $\mathrm{MiP}$ growth cones interact with muscle pioneers and whether muscle pioneers are necessary for their proper pathway selection. Although motor growth cones 
and muscle pioneers interact specifically, in the absence of muscle pioneers, $\mathrm{CaP}$ and $\mathrm{MiP}$ form normal arbors; however, their growth cones display unusual pathfinding behaviors. We conclude that muscle pioneers are intermediate targets that influence motor growth cone pathfinding but are unnecessary for establishing proper neuromuscular specificity.

\section{MATERIALS AND METHODS}

Animals. Embryos of the zebrafish, Danio rerio, were obtained from the Oregon breeding facility and maintained on a $14 \mathrm{hr} \mathrm{light} / 10 \mathrm{hr}$ dark cycle. Embryos were staged by hours postfertilization at $28.5^{\circ} \mathrm{C}(\mathrm{h})$ and by standard staging criteria (Kimmel et al., 1995). Segments were numbered as described previously (Hanneman et al., 1988). A hemisegment refers to a single myotome and the corresponding half of the spinal cord. Our observations were confined to segments $7-15$ of animals that ranged from $16 \mathrm{~h}$ to $48 \mathrm{~h}$. During experimental procedures, embryos older than $17 \mathrm{~h}$ were anesthetized in a $0.02 \%$ solution of tricaine-methanesulfonate (Sigma, St. Louis, MO) (Westerfield, 1995).

Intracellular and optical recordings. Electrophysiological measurements were made as described previously (Grunwald et al., 1988). Muscle contractions were recorded from unanesthetized embryos beginning at approximately $17 \mathrm{~h}$. In these experiments it was not always possible to be sure that the micropipette was positioned in one of the muscle pioneers. Embryos were visualized with a high resolution video camera (Dage) and recorded on video tape. Individual contractions were analyzed by playing back the video recording one frame at a time.

Immunohistochemistry. Whole-mount embryos were processed for immunoreactivity using monoclonal antibodies (mAbs) zn-5, znp-1, zn-1 (Trevarrow et al., 1990), or 4D9 (Patel et al., 1989) following procedures described in Eisen et al. (1989). The mAbs zn-5 (Hatta et al., 1991a; Trevarrow et al., 1990; Fashena, 1996) and 4D9 (Patel et al., 1989; Hatta et al., 1991a) recognize, respectively, cell surface and nuclear antigens expressed by muscle pioneers, and znp-1 (Melançon, 1994) and zn-1 (Eisen et al., 1989) recognize the cell bodies and axons of primary motoneurons; these are the only motoneurons extending beyond the common pathway at $24 \mathrm{~h}$ (Pike et al., 1992). The mAb F59 (Ig G1) (Crow and Stockdale, 1986) was used to detect all slow muscle cells (Devoto et al., 1996b), including muscle pioneers, on transverse sections following procedures described in Devoto et al. (1996b). Tissue culture supernatants were used at a dilution of 1:10.

Electron microscopy. Embryos were first fixed in $0.2 \%$ glutaraldehyde, $4 \%$ paraformaldehyde in fix buffer (FB; $0.15 \mathrm{~mm} \mathrm{CaCl}_{2}, 4 \%$ sucrose in $0.1 \mathrm{M} \mathrm{PO}_{4}$ buffer, $\mathrm{pH} \mathrm{7.3)} \mathrm{for} 1 \mathrm{hr}$ at $4^{\circ} \mathrm{C}$ (Eldred et al., 1983), and then fixed overnight at $4{ }^{\circ} \mathrm{C}$ in $4 \%$ paraformaldehyde and $0.1 \mathrm{M} \mathrm{NaHCO}_{3}$ at $\mathrm{pH}$ 10.0. After fixation, embryos were rinsed in FB, incubated in $1 \%$ sodium borohydride $\left(\mathrm{NaBH}_{4}\right)$ in $\mathrm{FB}$ for 30 min, rinsed again in $\mathrm{FB}$ for 30 min, and permeabilized in a buffered ethanol series as follows: 5 min each at $4^{\circ} \mathrm{C}$ in $10 \%, 25 \%, 40 \%, 25 \%, 10 \%$ ethanol in $\mathrm{FB}$ followed by a $30 \mathrm{~min}$ rinse in $\mathrm{FB}$ at room temperature.

Whole-mount embryos were processed for immunoreactivity with mAb znp-1 or zn-5 as described in Eisen et al. (1989). A few embryos were dehydrated in an ascending ethanol series, cleared in methyl salicylate, and mounted between coverslips so that they could be examined with Nomarski DIC optics to determine the extent of axonal projections in the segments under study. The remaining embryos were rinsed in 0.1 $\mathrm{M} \mathrm{PO}_{4}$ buffer (PB) for 30 min, post-fixed in $2 \%$ osmium tetroxide $\left(\mathrm{Os}_{4}\right)$ in $0.1 \mathrm{M} \mathrm{PB}$, dehydrated in an ascending ethanol series (10 min each in $30 \%, 50 \%, 70 \%, 85 \%, 95 \%, 95 \%, 100 \%, 100 \%$ ), cleared in propylene oxide, and embedded in Epon Araldite. Transverse sections were cut at 7-10 $\mu \mathrm{m}$, mounted on siliconized glass slides, and examined at $40 \times$ on a Zeiss Axioplan microscope. Sections of interest were reembedded in Epon Araldite (Schabtach and Parkening, 1974). Thin sections were cut at $\sim 100 \mathrm{~nm}$ in the original plane of section, mounted on Parlodioncoated 200 hexagonal mesh grids, stained with 5\% uranyl acetate and lead citrate, carbon-stabilized, and examined on a Phillips 300 electron microscope.

The approximate axial level of the somites was determined by counting the number of thick sections in which there were motoneurons labeled with the mAb znp-1. Thick sections in which $\mathrm{CaP}$ growth cones were visible near the muscle pioneers were selected for reembedding and thin sectioning.

Ablations. $\mathrm{CaP}$ was ablated by laser-irradiation as described in Eisen et al. (1989). An additional primary motoneuron, variable primary motoneuron $(\mathrm{VaP})$, resides adjacent to $\mathrm{CaP}$ in about half the trunk hemiseg- ments (Eisen et al., 1990). CaP and VaP form an equivalence pair (Eisen, 1992) in which they compete for the $\mathrm{CaP}$ fate. In hemisegments that contained both $\mathrm{CaP}$ and $\mathrm{VaP}$, both cells were ablated. Some ablations were performed with a dye-pumped [0.025\% coumarin 450, Exciton, Dayton, $\mathrm{OH}$ (in methanol)] pulse laser (MPDL-250, Cynosure, Bedford, MA) (Eisen et al., 1989, 1990; Pike and Eisen, 1990; Pike et al., 1992); others were performed with a self-contained nitrogen laser with a mirrorto-mirror configuration dye laser module $(0.043 \%$ coumarin 450 in methanol; VSL337ND and DLMS 210, Laser Science, Newton, MA).

$\mathrm{CaP}$ ablations were performed before or at the time of axogenesis, but before growth cone contact with muscle pioneers. Primary motoneurons ablated at these stages are not replaced (Eisen et al., 1989, 1990; Pike and Eisen, 1990). Ablation of primary motoneuron cell bodies that have undergone axogenesis eliminates the axon as well as the cell body (Pike et al., 1992). The success of all $\mathrm{CaP}$ or $\mathrm{CaP}$ and $\mathrm{VaP}$ ablations was determined by observation of the cell bodies using Nomarski DIC optics at the time of ablation or at the time of intracellular labeling (Eisen et al., 1989 ), or by immunolabeling the embryos with a mixture of the mAbs zn-1 and znp-1.

Muscle pioneers were ablated in one somite shortly after they elongated and before the time when the growth cones of motoneurons contacted them. The success of muscle pioneer ablations was verified either by fixing the embryos and labeling them with the 4D9 or zn-5 mAbs or by observation using Nomarski DIC optics. Control muscle ablations were performed by ablating muscle cells dorsal or ventral to the muscle pioneers.

Intracellular labeling. $\mathrm{CaP}$ and $\mathrm{MiP}$ were intracellularly labeled to assess their outgrowth and cell-specific trajectories. Individual motoneurons were labeled by intracellular injection of lysinated rhodamine dextran or lysinated fluorescein dextran $\left(3 \times 10^{3} M_{\mathrm{r}}\right)$ (Molecular Probes, Eugene, OR) as described previously (Raible et al., 1992). Embryos were mounted as described in Eisen et al. (1989).

Image processing. The development of labeled primary motoneurons was monitored using low light level, video-enhanced fluorescence microscopy. Images were captured on a Macintosh IIci computer using AxoVideo (Myers and Bastiani, 1991) (Axon instruments, Foster City, CA). Image processing included combining images from different focal planes, background subtraction, contrast enhancement, addition of pseudocolor, and combination of bright-field and fluorescent images; processing was performed using Adobe Photoshop (Mountain View, CA).

\section{RESULTS}

\section{Growth cones of primary motoneurons interact specifically with muscle pioneers}

Primary motoneurons extend growth cones out of the spinal cord directly to the muscle pioneers (Eisen et al., 1986) (Fig. 1B), which can be recognized in living embryos by their distinctive morphology (Fig. $2 A$ ) and in fixed embryos by their characteristic nuclear labeling with the 4D9 mAb (Fig. 2B) and cell-surface labeling with the $\mathrm{zn}-5 \mathrm{mAb}$ (Fig. $2 C$ ). Muscle pioneers first contracted (Fig. $3 A, B$ ) about the time that primary motor growth cones initially contacted them. These contractions were confined to muscle pioneers within individual myotomes, suggesting that the muscle pioneers in a particular myotome could be responding to the $\mathrm{CaP}$ growth cone from the spinal hemisegment at the same axial level. Within $1 \mathrm{hr}$, muscle fibers immediately adjacent to the muscle pioneers began contracting.

To learn whether these early muscle contractions were myogenic or were produced by cholinergic activation as occurs later in development (Grunwald et al., 1988), we recorded the transmembrane potential of muscle fibers with intracellular micropipettes. In most cases in which stable recordings were obtained (64 of 87 fibers in 37 embryos), we observed spontaneous depolarizations of the muscle membrane potential (Fig. 3C, top trace). These depolarizations were associated with muscle contractions as determined by watching through the microscope while recording (15 fibers in five embryos). The addition of curare to the bathing medium blocked both the depolarizations (Fig. 3C, bottom trace) 
A

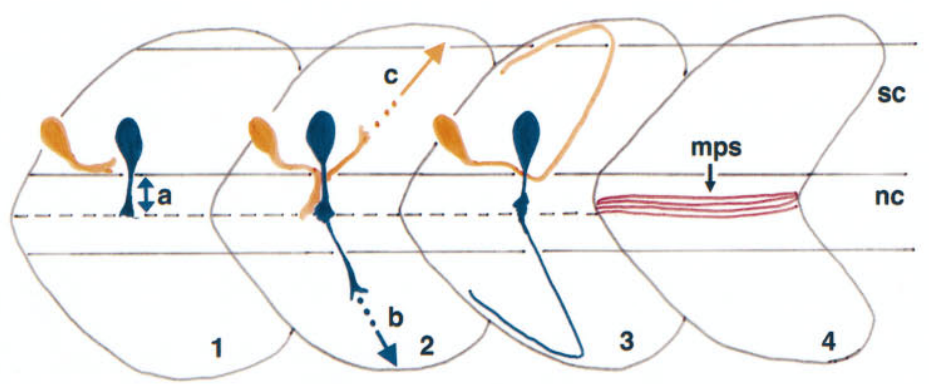

B

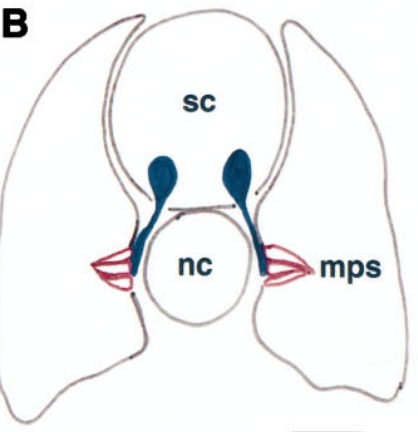

\section{Figure 1}
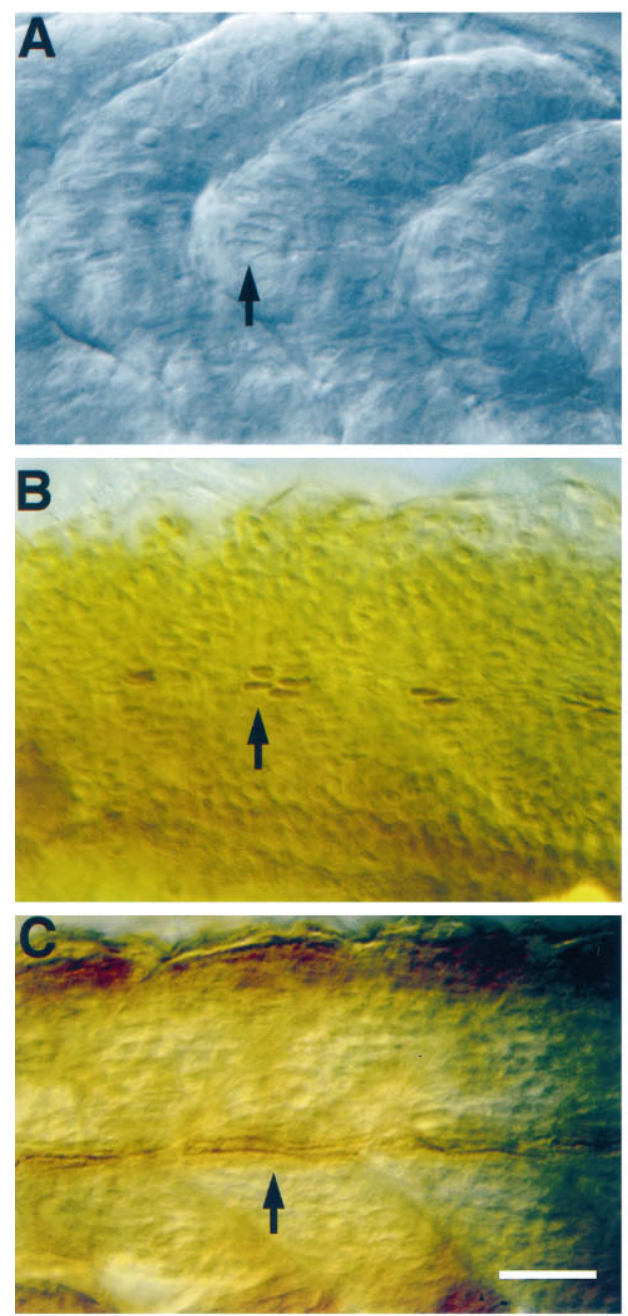

Figure 2

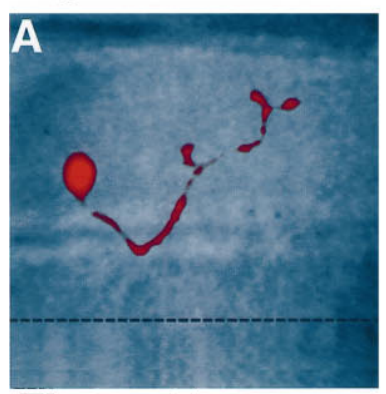

Figure 7
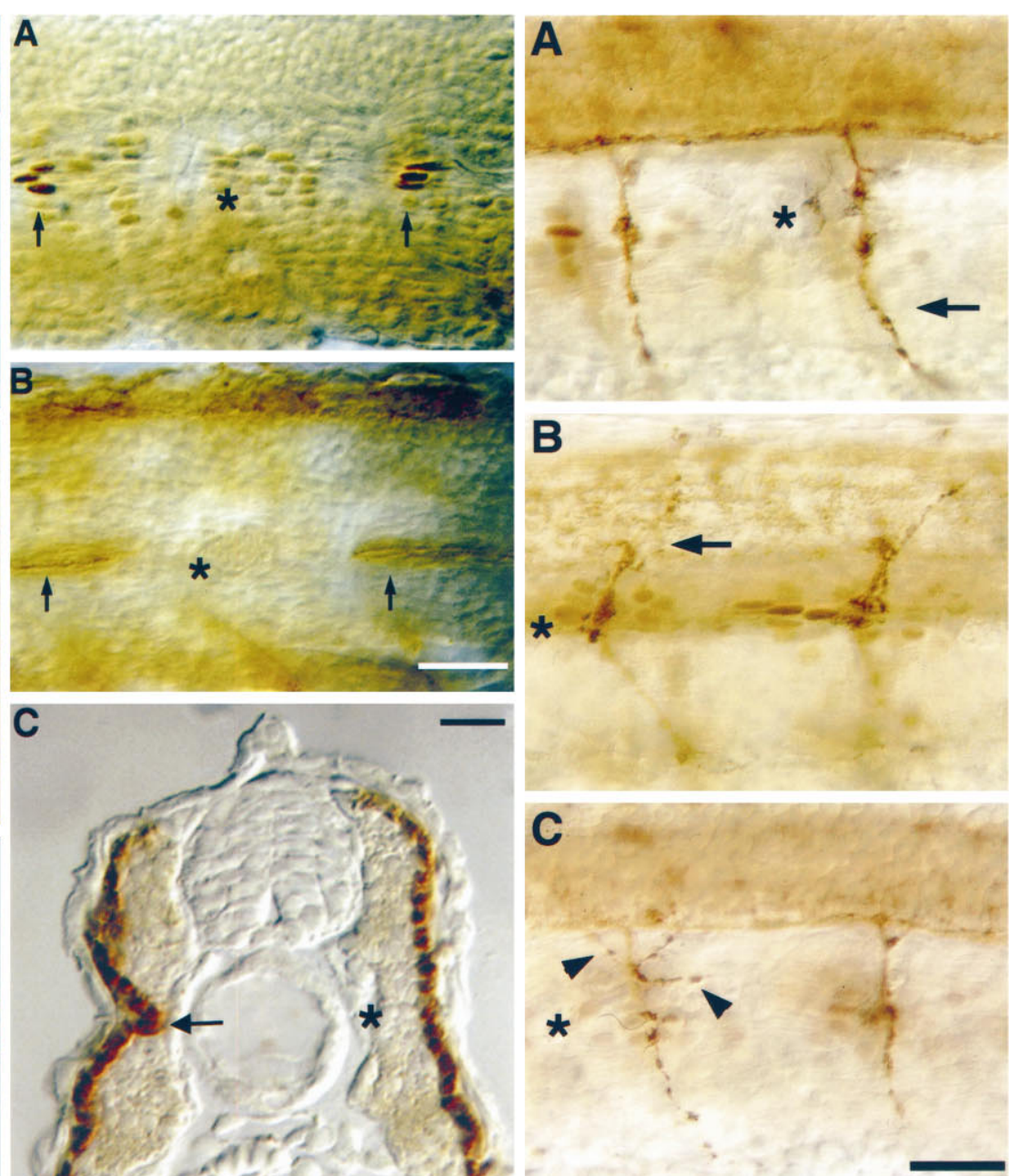

Figure 5

\section{Figure 6}
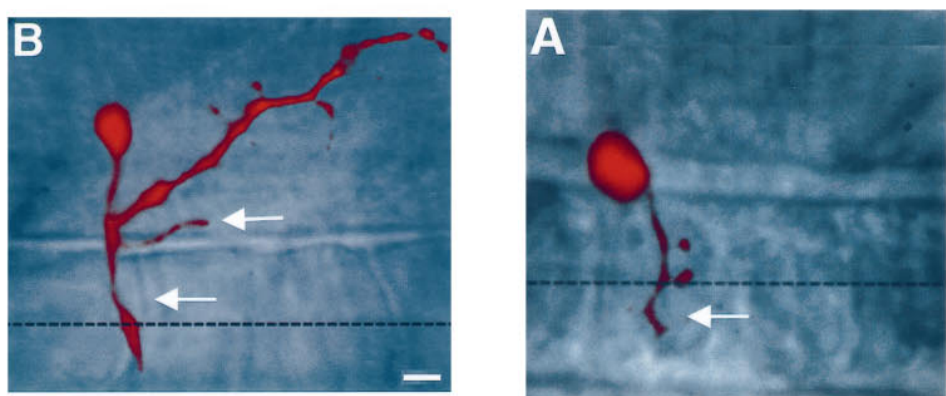

Figure 8

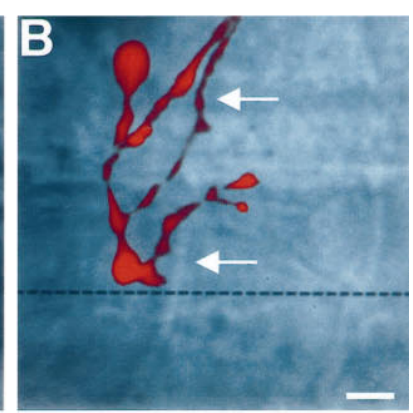


and the contractions (15 fibers in five embryos). Our previous work has shown that by this stage, muscle pioneers are the only muscle cells that have clustered acetylcholine receptors (Liu and Westerfield, 1992). Thus, these contractions seem to be the result of cholinergic activation.

Fine-structural analysis revealed contacts between primary motoneuron growth cones and muscle pioneers (Fig. 4). Doublelabeling with the zn-5 (not shown) and znp-1 mAbs allowed us to recognize both the muscle pioneers and the $\mathrm{CaP}$ growth cone. The $\mathrm{CaP}$ growth cone and axon were closely associated with the surface of the muscle pioneers, the basal lamina of the notochord, and other migratory cells that are probably neural crest cells (Raible et al., 1992). There were sites of close membrane apposition between muscle pioneers and $\mathrm{CaP}$ axons; intense antibody labeling of motor axons did not allow us to determine whether synaptic vesicles were present near regions of close apposition or to examine fine structural details. The MiP growth cone also contacted the muscle pioneers at later stages (not shown). Because znp-1 labels both $\mathrm{CaP}$ and $\mathrm{MiP}$ axons, it was unclear whether only one or both axons form close appositions with muscle pioneers.

\section{Muscle pioneers seem to be unnecessary for formation of normal axonal trajectories}

To learn whether muscle pioneers are required for pathway selection by primary motoneurons, we eliminated them by laserirradiation 1-2 hr before motor axon contact. In control experiments we eliminated muscle cells immediately dorsal or ventral to the muscle pioneers. We first tested whether muscle pioneers were replaced after laser-irradiation by ablating them, allowing the embryos to develop for 5-7 hr, and examining whether muscle pioneers had been replaced by labeling embryos with the 4D9, zn-5, or F59 mAbs. As shown in Figure 5, laser-irradiation at 16 $\mathrm{h}$ eliminated the muscle pioneers apparently without affecting surrounding muscle cells, and the muscle pioneers were not replaced by $24 \mathrm{~h}$ ( 80 segments in 71 embryos).

Absence of muscle pioneers or adjacent muscle cells seemed to have little effect on the final axonal trajectories of $\mathrm{CaP}$ and MiP. We assessed whether $\mathrm{CaP}$ and $\mathrm{MiP}$ growth cones formed normal morphologies by examining them several hours after muscle pioneer ablation at a time when they each had developed a cellspecific axonal trajectory. Embryos were allowed to develop for 5-7 hr after muscle pioneer ablation. They were then fixed and

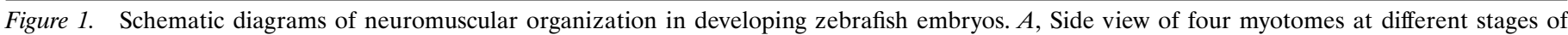

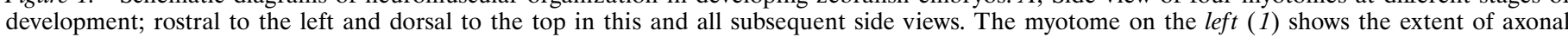

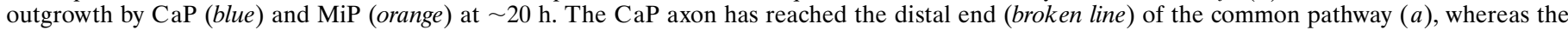

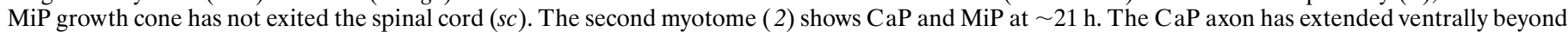

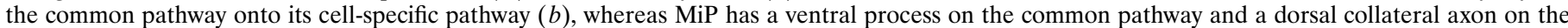

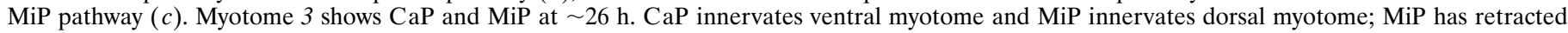

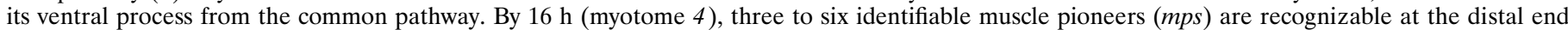

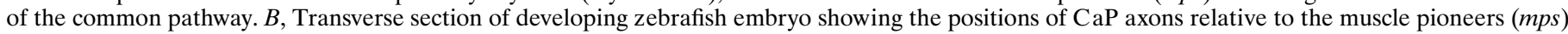
at $\sim 20$ h. $n c$, Notochord. Scale bar, $25 \mu \mathrm{m}$.

Figure 2. Muscle pioneers have a distinct morphology and express specific markers. Side views of a living embryo $(A)$ and two immunolabeled embryos $(B, C) . A$, Nuclei of the muscle pioneers (arrow) are visible at the rostral apex of the chevron-shaped somite. Muscle pioneers elongate to span the somite along the anterior-posterior axis and flatten, eventually extending from the notochord to the lateral surface of the myotome. $B$, Muscle pioneer nuclei are labeled by the 4D9 antibody (Patel et al., 1989), which recognizes three Engrailed (Eng) proteins (Hatta et al., 1991a); muscle pioneers express Eng1 and Eng2 (Ekker et al.; 1992). This marker intensely labels muscle pioneer nuclei, whereas surrounding muscle cell nuclei are only faintly labeled. $C$, The mAb zn-5 (Trevarrow et al., 1990; Hatta et al., 1991a) recognizes a cell surface antigen, DM-Grasp, (Fashena, 1996) which is present on adaxial cells (Devoto et al., 1996b) including muscle pioneers (arrow). Scale bar, $25 \mu \mathrm{m}$.

Figure 5. Ablation by laser-irradiation eliminates muscle pioneers without affecting surrounding muscle cells. Side views of two whole-mount embryos at $24 \mathrm{~h}$ labeled with 4D9 $(A)$ or zn-5 $(B)$ mAbs. The asterisks mark experimental segments in which muscle pioneers were ablated, and arrows point to muscle pioneers in adjacent segments. $C$, Transverse section of embryo at $24 \mathrm{~h}$ labeled with F59. The asterisk marks experimental segment in which muscle pioneers were ablated, and the arrow points to muscle pioneers on the contralateral side. Except for the absence of muscle pioneers, the slow muscle cells on the experimental side appear normal. Because slow muscle cells have not been observed to divide (Devoto et al., 1996), this suggests that ablation of muscle pioneers has no effect on neighboring muscle cells. Scale bars: $A, B, 25 \mu \mathrm{m} ; C, 20 \mu \mathrm{m}$.

Figure 6. $\mathrm{CaP}$ and $\mathrm{MiP}$ form normal arbors after muscle pioneer ablation. Side views of three whole-mount embryos at $24 \mathrm{~h}$ after laser-irradiation and immunostaining with 4D9 and znp-1. A, CaP axon (arrow) in experimental segment (asterisk) is similar to CaP axon in control segment (left). B, MiP axon (arrow) in experimental segment (asterisk) is similar to MiP axon in control segment (right); 30 of 31 experimental segments had normal MiP axons. Infrequent perturbations such as ectopic branching $(C$, arrowheads) were observed in experimental segments (asterisks) but not in control segments (right). In 12 of 47 cases, ectopic branching was observed at the following positions: along the common pathway (7 of 12), in the ventral myotome (4 of 12 ), or along the common pathway and in the ventral myotome (1 of 12). Scale bar, $25 \mu \mathrm{m}$.

Figure 7. MiP retains its ventral process in the absence of muscle pioneers. $A$, An intracellularly labeled control MiP at $24 \mathrm{~h}$ in a living embryo; this cell had retracted its ventral process and extended an axon dorsally. $B$, An intracellularly labeled experimental MiP in a living embryo at $48 \mathrm{~h}$ in the absence of muscle pioneers. The ventral process extended beyond the distal limit of the common pathway (broken line) onto the CaP pathway and had not retracted. Ectopic branching (arrows) was observed in 6 of 27 embryos at $48 \mathrm{~h}$. Scale bar, $10 \mu \mathrm{m}$.

Figure 8. $\mathrm{CaP}$ and the muscle pioneers may regulate retraction of the MiP ventral process. Side view of an MiP labeled intracellularly after muscle pioneer and $\mathrm{CaP}$ ablation and viewed in the living embryo at two time points. $A$, At $24 \mathrm{~h} \mathrm{MiP}$ had a ventral process (arrow) that extended beyond the distal limit of the common pathway (broken line) and did not have a dorsal collateral (see control MiP) (Fig. $7 A$ ). Ectopic branches were present in 17 of 41 experimental segments at $24 \mathrm{~h} . B$, At $48 \mathrm{hr}$ most of the ventral process was still present, and ectopic branches (arrows) had sprouted from it, although a normal dorsal process had formed. The extent of the dorsal projection was normal, although the entire extent is not shown here. Ectopic branches were present in 6 of 16 experimental segments at $48 \mathrm{~h}$. Scale bar, $10 \mu \mathrm{m}$. 

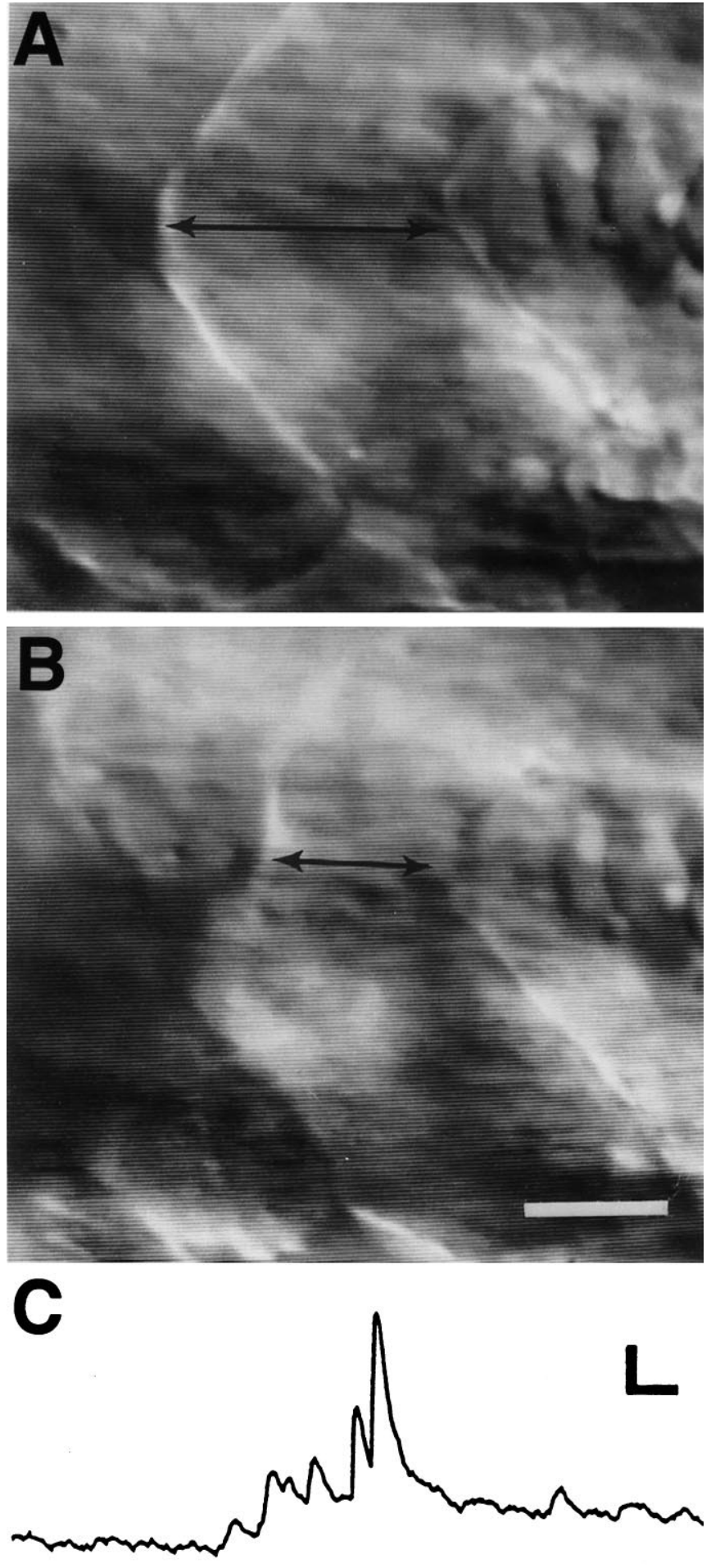

Figure 3. Early muscle contractions are produced by cholinergic activation. The muscle pioneers are the first fibers to twitch. Video micrographs were recorded from a $19.5 \mathrm{~h}$ embryo before $(A)$ and $300 \mathrm{msec}$ after $(B)$ the onset of a spontaneous twitch. The only fibers actively contracting in this myotome were the muscle pioneers, which are located at the arrows. This result was observed in 18 of 20 myotomes in 15 embryos. $C$, Intracellular recordings were obtained from a muscle pioneer at $19 \mathrm{~h}$, a immunolabeled with the zn-1, znp-1, and 4D9 mAbs, and the $\mathrm{CaP}$ - and MiP-specific axonal trajectories (Fig. $1 A$ ) and presence or absence of muscle pioneers were examined. In experimental segments from which muscle pioneers were absent, most CaPs projected normally (Fig. $6 A$ ), although some had shorter axons or aberrant branches at $24 \mathrm{~h}$ (Fig. $6 C$, Table 1). Most MiPs projected a normal dorsal axon after muscle pioneer ablation (Fig. 6B). All $\mathrm{CaPs}$ and MiPs had normal projections after control ablations (CaP, $n=10$; MiP, $n=5$; data not shown). The antibodies used to assess primary motoneuron trajectories label all primary motoneurons; therefore, it is possible that some abnormal branches along the common pathway were from the MiP ventral process.

\section{Muscle pioneers delineate the extent of the common pathway}

By several hours after muscle pioneer ablation, most $\mathrm{CaPs}$ and MiPs had normal axonal trajectories, although there were often abnormal branches as well; however, because znp-1 mAb labeling does not distinguish between $\mathrm{CaP}$ and $\mathrm{MiP}$ axons, we could not resolve which axons had abnormal branches along the common pathway. Furthermore, $\mathrm{CaP}$ and $\mathrm{MiP}$ axons could be examined only at a single time point, preventing us from observing dynamic or transient changes that might result from muscle pioneer ablations. Thus, we could not determine whether CaPs with short axons at $24 \mathrm{~h}$ had arrested growth cones or simply had delayed growth cone extension. To circumvent these problems, we labeled individual motoneurons with fluorescent vital dyes shortly after muscle pioneer ablation and observed them periodically during axonal extension.

Labeled CaPs and MiPs responded differently to muscle pioneer ablation. All CaP axons projected normally to ventral muscle by $30 \mathrm{~h}$ (Table 1 ), showing that those CaPs with short axons at $24 \mathrm{~h}$ were delayed rather than arrested. All CaPs also projected normally in control ablations ( $n=10$; data not shown). In contrast, MiP axons sometimes extended their growth cones beyond the position of the now absent muscle pioneers (Figs. $7 B$, $9 C)$. This observation is significant because MiPs never extended growth cones beyond the muscle pioneers (Figs. 7A, 9C) in control segments without ablations $(n=13)$ or in segments with control ablations $(n=5)$. The MiPs with long ventral processes also had abnormal branches along the common pathway, and they retained these ventral processes beyond $48 \mathrm{~h}$ (Figs. 7B, 9C), a time by which all control MiPs had retracted the ventral process. All individually labeled CaPs and MiPs were normal after control ablations (Fig. 9).

\section{$\mathrm{CaP}$ and the muscle pioneers may regulate retraction of the MiP ventral process}

The muscle pioneers may delineate a region in which signaling occurs between several different cells. In this region, $\mathrm{CaP}$ and MiP axons have specialized contacts with one another (data not shown) in addition to specialized contacts with muscle pioneers. In previous studies (Pike and Eisen, 1990), after CaP ablation, many more MiPs retained their ventral processes than control MiPs, although these aberrant ventral processes rarely extended along the CaP-specific pathway, distal to the muscle pioneers (Fig. 9). These results suggest that although $\mathrm{CaP}$ is not required

time at which the $\mathrm{CaP}$ growth cone had reached the muscle pioneers and contractions were observed. Spontaneous muscle activity was recorded in normal saline (top trace) but was blocked (bottom trace) by adding the cholinergic antagonist curare $\left(10^{-4} \mathrm{M}\right)$. Resting potential, $-68 \mathrm{mV}$. Calibration: $2 \mathrm{mV}, 10 \mathrm{msec}$. Scale bar (for $A$ and $B$ ): $20 \mu \mathrm{m}$. 


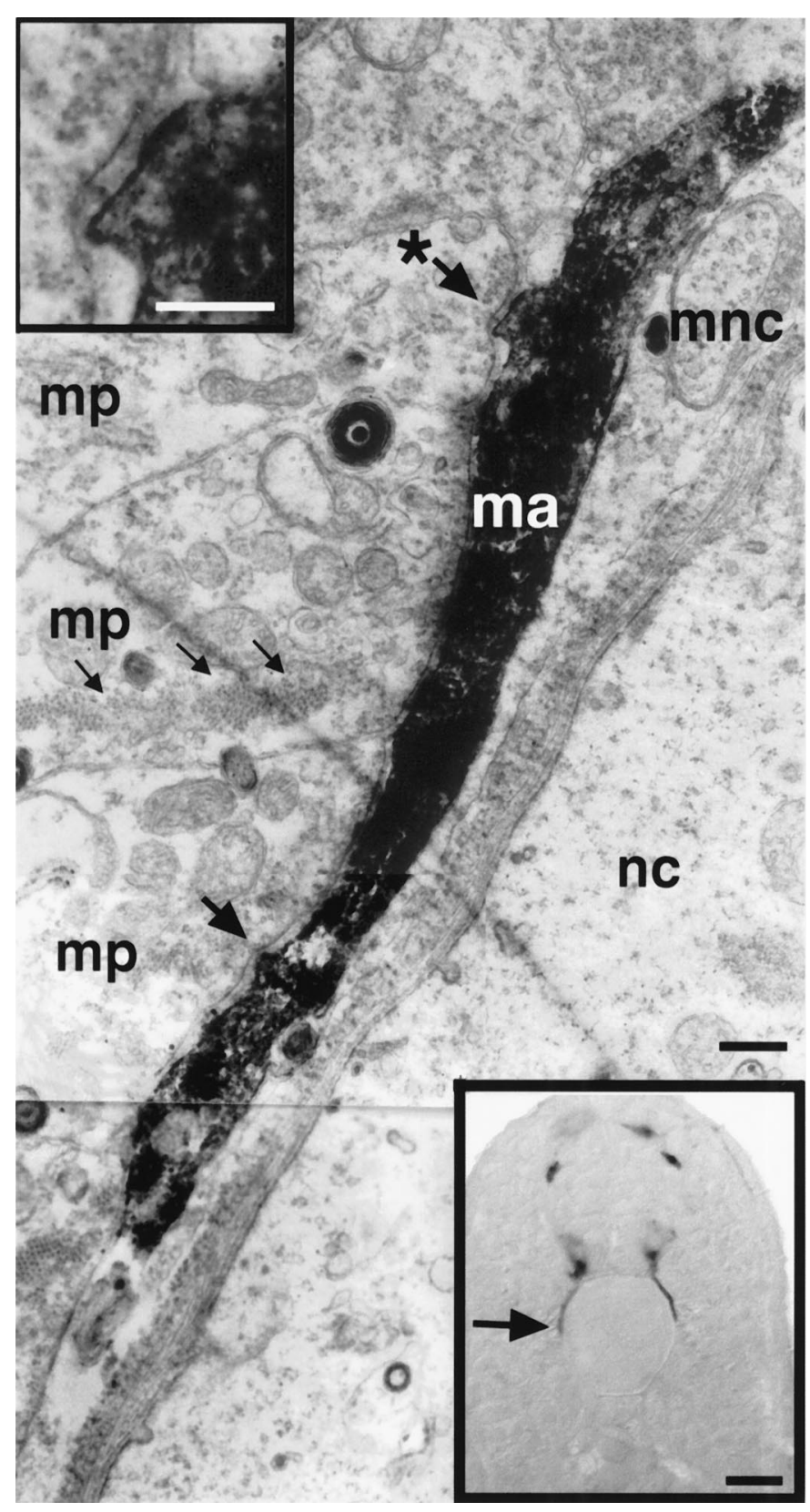

Figure 4. The $\mathrm{CaP}$ axon $(m a)$ contacts the muscle pioneers $(m p)$. Electron micrograph of somite 12 in a $19 \mathrm{~h}$ embryo. Electron density in $\mathrm{CaP}$ axon is attributable to znp-1 labeling. Organized contractile elements (small arrows) are present in muscle pioneers but not in other surrounding muscle cells at this time. Large arrows show regions of close apposition between the $\mathrm{CaP}$ growth cone and muscle pioneers. The top left inset shows one of these regions (asterisk) at higher magnification. The cell (mnc) between the notochord $(n c)$ and motor axon $(m a)$ seems to be migrating. Two cell types have been described to migrate through this region: sclerotome (MorinKensicki and Eisen, 1997) and neural crest (Raible et al., 1992). On the basis of the timing of these cellular migrations and the stage of the embryo shown here, this cell is probably a neural crest cell. Bottom right inset shows the thick section from which this thin section was cut, and the arrow points to the region shown in the electron micrograph. Scale bars: bottom right inset, $20 \mu \mathrm{m}$; electron micrograph, $2 \mu \mathrm{m}$; top left inset, $1 \mu \mathrm{m}$.

for MiP pathfinding, it may participate in the mechanism that leads to the retraction of the MiP ventral process. Thus, removal of both the muscle pioneers and $\mathrm{CaP}$ might be expected to affect MiP pathfinding.
We examined whether the muscle pioneers and $\mathrm{CaP}$ might act together to influence MiP axonal extension or pathway selection by ablating the muscle pioneers and $\mathrm{CaP}$ at the same axial level. MiPs were labeled intracellularly 3-5 hr after the ablation and were followed to $48 \mathrm{~h}$ when possible. At $24 \mathrm{~h}$, in 13 of 41 cases, the labeled $\mathrm{MiP}$ extended a growth cone ventrally past the region from which muscle pioneers were now absent and had abnormal branches along this ventral axon (Figs. $8 A$, 9). MiPs were followed through $48 \mathrm{~h}$ in 16 of 41 experimental segments. In 6 of these 16 cases ventral processes were retained through $48 \mathrm{~h}$ (Figs. $8 B$, Fig. 9). Despite this abnormal ventral process, in each case the MiP extended a normal dorsal axon. These results suggest that $\mathrm{CaP}$ and the muscle pioneers act coordinately to regulate the length of the MiP ventral process and the timing of its retraction.

\section{DISCUSSION}

\section{Muscle pioneers are intermediate targets for primary motoneurons}

We observed both morphological and functional interactions between growth cones of identified motoneurons and muscle pioneers. Our fine-structural analysis revealed a common feature of developing nerve-muscle contacts (Kelly and Zacks, 1969): motor growth cones form regions of close membrane appositions with muscle cells during outgrowth. In developing zebrafish, these regions form specifically between growth cones of identified primary motoneurons and muscle pioneers. Because muscle pioneers are the first cells to assemble contractile elements, to cluster acetylcholine receptors (Liu and Westerfield, 1992), and to contract, and because these contractions can be blocked with cholinergic antagonists, these regions of apposition probably represent sites of neuromuscular transmission. These observations suggest that the early functional interactions between zebrafish primary motoneurons and muscle pioneers are attributable to release of transmitter from the growth cone, as described previously for cultured Xenopus laevis spinal neurons (Young and Poo, 1983; Chow and Poo, 1985; Sun and Poo, 1985) and cultured chick ciliary ganglion neurons (Hume et al., 1983). Transmitter release may provide a mechanism for growth cones to interact with or modify their immediate environment (Bentley and O'Connor, 1994; Kater and Rehder, 1995). Embryos homozygous for a mutation in the nic-1 gene, which encodes a nicotinic acetylcholine receptor subunit (Sepich and Westerfield, 1993), lack functional acetylcholine receptors. The observation that motoneurons in nic-1 mutant embryos form normal neuromuscular connections with muscles in the absence of transmitter activation argues against a receptor-mediated requirement for transmitter signaling during pathfinding (Westerfield et al., 1990).

\section{Muscle pioneers influence axonal extension but not final axonal morphology}

Our observations showing specific interactions between primary motor growth cones and muscle pioneers and our previous work showing that primary motor growth cones extend directly to muscle pioneers (Eisen et al., 1986; Myers et al., 1986) raised the possibility that signals from muscle pioneers might regulate primary motor growth cone extension or pathway choice. Guidepost cells in the developing grasshopper leg (Bentley and Caudy, 1983), and floor plate in the developing rat (Altman and Bayer, 1984; Dodd and Jessell, 1988; Bovolenta and Dodd, 1990; Kennedy et al., 1994; Serafini et al., 1994; Kennedy and TessierLavigne, 1995) and in zebrafish neural tube (Hatta et al., 1991b; Bernhardt et al., 1992a,b) have been shown to influence axonal 
Table 1. CaP axon morphology after muscle pioneer ablation

\begin{tabular}{|c|c|c|c|c|c|c|}
\hline & \multicolumn{2}{|c|}{$\begin{array}{l}\text { Immunolabel } \\
\text { experimental } \\
(24 \mathrm{~h})\end{array}$} & \multicolumn{2}{|c|}{$\begin{array}{l}\text { Intracellular label } \\
\text { experimental } \\
(30 \mathrm{~h})\end{array}$} & \multicolumn{2}{|c|}{$\begin{array}{l}\text { Intracellular label } \\
\text { control } \\
(30 \mathrm{~h})\end{array}$} \\
\hline & $n$ & $(\%)$ & $n$ & $(\%)$ & $n$ & $(\%)$ \\
\hline Normal axon $^{a}$ & 47 & 84 & 13 & 100 & $118^{b}$ & 100 \\
\hline Short axon ${ }^{c}$ & 9 & 16 & 0 & 0 & 0 & 0 \\
\hline Total CaPs examined & 56 & 100 & 13 & 100 & 118 & 100 \\
\hline
\end{tabular}

${ }^{a}$ No obvious difference in length or pathway choice between experimental and control CaPs, although some had abnormal branches (see Fig. 6).

${ }^{b}$ Data from Eisen et al. (1986), 64 CaPs; (1990), 28 CaPs; Liu and Westerfield (1990), 26 CaPs.

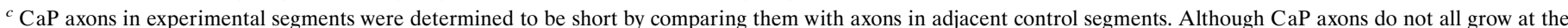

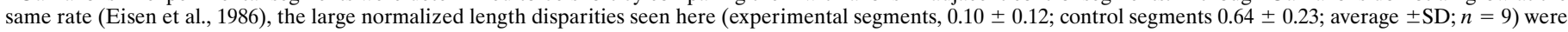
confined to segments in which the muscle pioneers were ablated.

outgrowth. In our studies, however, removal of muscle pioneers altered neither the initial direction of motor growth cone extension nor the final axonal trajectory, showing that primary motoneurons can establish normal morphologies in the absence of these cells.

Although muscle pioneers do not seem to be essential for initial outgrowth or specific pathway choice by primary motoneurons, they may provide a choice point for motor growth cones. Some $\mathrm{CaP}$ axons paused for an abnormally long time after muscle pioneer removal. Furthermore, in the absence of muscle pioneers, some MiPs extended a ventral process past the muscle pioneer region along the proximal portion of the $\mathrm{CaP}$-specific pathway on the ventral myotome, and this process was retained much longer than normal. Thus, muscle pioneers seem to prevent continued extension of the MiP ventral process. This role is similar to that described for muscle pioneers in insects (Ball et al., 1985) and suggests that in both vertebrates and insects, specific muscle fibers have important roles in motoneuron development in addition to their later functions in movement.

Retention of the aberrant $\mathrm{MiP}$ ventral process was enhanced after ablation of both $\mathrm{CaP}$ and the muscle pioneers, suggesting that $\mathrm{CaP}$ and the muscle pioneers normally collaborate to influence retraction of the MiP ventral process. We do not know whether ventral process retraction is functionally significant. It seems that the ventral myotome is a nonpermissive environment for MiP arborization (Gatchalian and Eisen, 1992). This nonpermissiveness may also contribute to retraction of the MiP ventral process. Thus, as for insect sensory neurons (Bentley and Caudy,
A

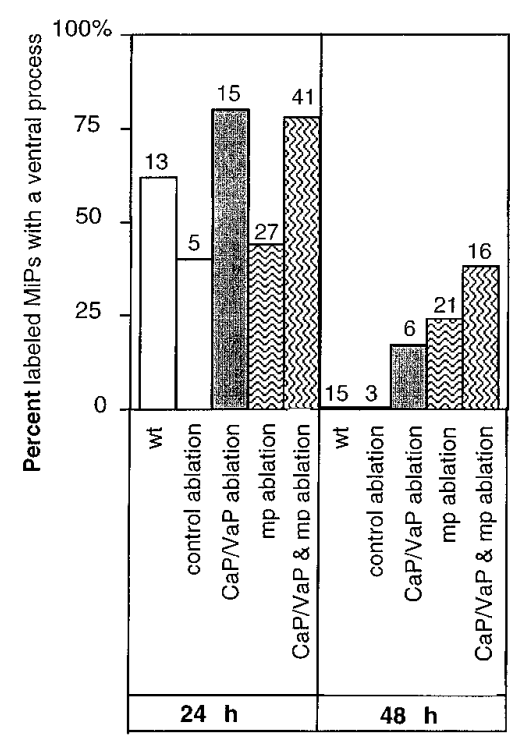

$\mathbf{B}$

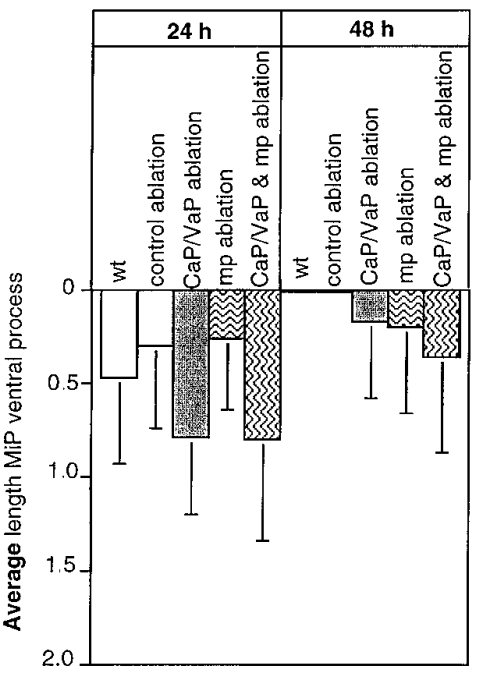

C

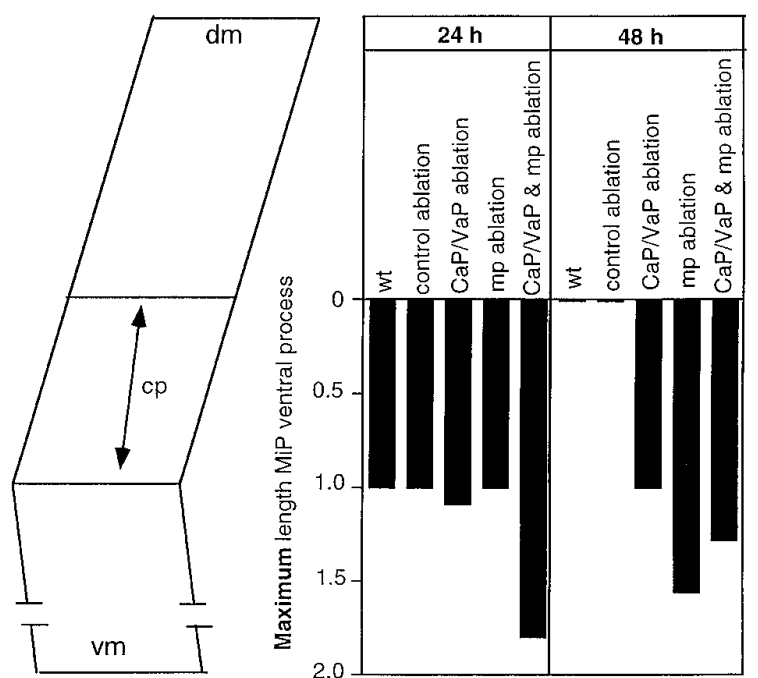

Figure 9. Ablations affect MiP ventral process length and retention. A, Percentage of intracellularly labeled MiPs, which had a ventral process at $24 \mathrm{~h}$ and $48 \mathrm{~h}$ after ablation of cell types that could potentially affect pathfinding. At $24 \mathrm{~h}$, both $\mathrm{CaP} / \mathrm{VaP}$ ablation and the ablation of $\mathrm{CaP} / \mathrm{VaP}$ and the muscle pioneers $(C a P / V a P \& m p$ ablation $)$ seem to influence ventral process retention. At $48 \mathrm{~h}$, all control MiPs have entirely retracted the ventral process, whereas many MiPs in experimental segments still have a ventral process. $B$, Average length $( \pm \mathrm{SD})$ and $(C)$ maximum length of all MiP ventral processes examined. The lengths of MiP ventral processes were measured and normalized such that the total distance along the common pathway $(c p$ in schematic somite between $B$ and $C$ ) was 1.0 [ 0 = exit point from spinal cord; $1.0=$ distal end of common pathway where the muscle pioneers reside; values $>1.0$ reflect axons that extended beyond the muscle pioneers along the CaP-specific pathway into ventral myotome $(\mathrm{vm})$; $d \mathrm{~m}$, dorsal myotome]. The average process lengths $(B)$ were calculated from the cells shown in $A$, and they illustrate the variability in process length, particularly at $24 \mathrm{~h}$. By $48 \mathrm{~h}$, only experimental MiPs still retained a ventral process. The maximum process lengths $(C)$ show that only in experimental conditions did the MiP ventral process extend beyond the level of the muscle pioneers and suggest that muscle pioneer ablation and ablation of $\mathrm{CaP} / \mathrm{VaP}$ and muscle pioneers together affect ventral process lengths and retention more than $\mathrm{CaP} / \mathrm{VaP}$ ablation alone. $\mathrm{CaP} / \mathrm{VaP}$ ablation data are from previously reported experiments (Pike and Eisen, 1990). 
1983) and for vertebrate commissural neurons (Dodd and Jessell, 1988; Bovolenta and Dodd, 1990; Hatta et al., 1991b; Bernhardt et al., 1992a,b; Kennedy et al., 1994; Serafini et al., 1994; Kennedy and Tessier-Lavigne, 1995), vertebrate motoneurons apparently use multiple cues to establish their morphology and target specificity. This idea is supported by other recent studies in zebrafish that imply functional redundancy in motoneuronal pathfinding. For example, no tail (ntl) (Halpern et al., 1993) mutants, which lack muscle pioneers, establish motor nerves similar to those seen in wild-type embryos, although individually labeled primary motoneurons in $n t l$ mutants exhibit defects similar to those seen in our ablation studies (J. S. Eisen and E. Melançon, unpublished observations). In addition, although a notochord-dependent signal alters the permissiveness of dorsal myotome for $\mathrm{CaP}$ axonal outgrowth, $\mathrm{CaP}$ axons still project ventrally even when both dorsal and ventral regions of the myotome remain permissive (Beattie and Eisen, 1997), showing that other cues are likely to be involved in directional guidance. Perhaps similar signals alter the permissiveness of ventral myotome for the MiP ventral process, helping to limit the maximum length of this process both normally and after muscle pioneer ablation. Thus, it seems likely that multiple signals function in various aspects of axonal pathfinding.

Adaxial cells, which are slow muscle precursors (Devoto et al., 1996a,b) first recognizable adjacent to the notochord in the segmental plate (Thisse et al., 1993), may regulate aspects of motoneuronal pathfinding. Muscle pioneers are a subset of adaxial cells (Devoto et al., 1996b). Shortly after adaxial cells become incorporated into somites, they elongate to form a sheet of muscle cells along the medial surface of the somite. This population of cells then migrates laterally through the somite to form a monolayer of slow muscle fibers on the lateral surface of the myotome. Adaxial cells begin migrating laterally about the time primary motor growth cones extend into the periphery (Eisen et al., 1986; Myers et al., 1986; Devoto et al., 1996b), thus the position and timing of adaxial cell migration are appropriate for their involvement in motoneuronal pathfinding. It is currently unknown whether muscle pioneers alone influence primary motor growth cone extension, whether other adaxial cells share similar properties, or whether adaxial cells contribute to primary motoneuron pathfinding in other ways. Examination of mutants that lack adaxial cells will clarify the role of these cells in motor growth cone navigation.

Our data are consistent with a model in which the muscle pioneers and $\mathrm{CaP}$ work synergistically to help regulate the initial length and later retraction of the ventral process of MiP. We suggest that the muscle pioneers may produce a signal that prevents $\mathrm{MiP}$ from extending its ventral process onto the $\mathrm{CaP}$ pathway. This idea is supported by the observation that neither VaP (Eisen et al., 1990) nor rostral primary neuron (Eisen et al., 1986) growth cones extend beyond the muscle pioneers onto the $\mathrm{CaP}$ pathway. The $\mathrm{CaP}$ growth cone is able to extend beyond the muscle pioneers onto its cell-specific pathway, whereas other primary motoneurons are not, suggesting that signaling from the muscle pioneers may affect only primary motoneurons whose growth cones extend later than $\mathrm{CaP}$. Identification of molecular signals produced by muscle pioneers should reveal the various roles played by these cells in the cell-specific pathfinding by the primary motoneurons.

\section{REFERENCES}

Altman J, Bayer SA (1984) The development of the rat spinal cord. Adv Anat Embryol Cell Biol 85:1-164.
Ball EE, Ho RK, Goodman CS (1985) Development of neuromuscular specificity in the grasshopper embryo: guidance of motoneuron growth cones by muscle pioneers. J Neurosci 5:1808-1819.

Beattie CE, Eisen JS (1997) Notochord alters the permissiveness of myotome for pathfinding by an identified motoneuron in embryonic zebrafish. Development 124:713-720.

Bentley D, Caudy M (1983) Pioneer axons lose directed growth after selective killing of guidepost cells. Nature 304:62-65.

Bentley D, Keshishian H (1982) Pathfinding by peripheral pioneer neurons in grasshoppers. Science 218:1082-1088.

Bentley D, O'Connor TP (1994) Cytoskeletal events in growth cone steering. Curr Opin Neurobiol 4:43-48.

Bernhardt RR, Nguyen N, Kuwada JY (1992a) Growth cone guidance by floor plate cells in the spinal cord of zebrafish embryos. Neuron 8:869-882.

Bernhardt RR, Patel CK, Wilson SW, Kuwada JY (1992b) Axonal trajectories and distribution of GABAergic spinal neurons in wildtype and mutant zebrafish lacking floor plate cells. J Comp Neurol 326:263-272.

Bovolenta P, Dodd J (1990) Guidance of commissural growth cones at the floor plate in embryonic rat spinal cord. Development 109:435-447.

Bovolenta P, Dodd J (1991) Perturbation of neuronal differentiation and axon guidance in the spinal cord of mouse embryos lacking a floor plate: analysis of Danforth's short-tail mutation. Development 113:625-639.

Chow I, Poo MM (1985) Release of acetylcholine from embryonic neurons upon contact with muscle cell. J Neurosci 5:1076-82.

Crow MT, Stockdale FE (1986) Myosin expression and specialization among the earliest muscle fibers of the developing avian limb. Dev Biol 113:238-254.

Devoto SH, Melançon E, Amacher SL, Eisen JS, Westerfield M (1996a) Influence of axial mesoderm on the development of slow muscle precursors. Dev Biol 175:386.

Devoto SH, Melançon E, Eisen JS, Westerfield M (1996b) Identification of separate slow and fast muscle precursor cells in vivo, prior to somite formation. Development 122:3371-3380.

Dodd J, Jessell TM (1988) Axon guidance and the patterning of neuronal projections in vertebrates. Science 242:692-699.

Dodd J, Morton SB, Karagogeos D, Yamamoto M, Jessell TM (1988) Spatial regulation of axonal glycoprotein expression on subsets of embryonic spinal neurons. Neuron 1:105-116.

Eisen JS (1992) The role of interactions in determining cell fate of two identified motoneurons in the embryonic zebrafish. Neuron 8:231-240.

Eisen JS, Myers PZ, Westerfield M (1986) Pathway selection by growth cones of identified motoneurones in live zebra fish embryos. Nature 320:269-271.

Eisen JS, Pike SH, Debu B (1989) The growth cones of identified motoneurons in embryonic zebrafish select appropriate pathways in the absence of specific cellular interactions. Neuron 2:1097-1104.

Eisen JS, Pike SH, Romancier B (1990) An identified motoneuron with variable fates in embryonic zebrafish. J Neurosci 10:34-43.

Ekker M, Wegner J, Akimenko MA, Westerfield M (1992) Coordinate embryonic expression of three zebrafish engrailed genes. Development 116:1001-1010.

Eldred WD, Zucker C, Karten HJ, Yazulla S (1983) Comparison of fixation and penetration enhancement techniques for use in ultrastructural immunocytochemistry. J Histochem Cytochem 31:285-292.

Fashena DS (1996) A neuron's reach can exceed its grasp: expression of a cell adhesion molecule in the zebrafish embryo. PhD thesis, University of Oregon.

Felsenfeld AL, Curry M, Kimmel CB (1991) The fub-1 mutation blocks initial myofibril formation in zebrafish muscle pioneer cells. Dev Biol 148:23-30.

Frank E, Wenner P (1993) Environmental specification of neuronal connectivity. Neuron 10:779-785.

Gatchalian CL, Eisen JS (1992) Pathway selection by ectopic motoneurons in embryonic zebrafish. Neuron 9:105-112.

Goodman CS, Shatz CJ (1993) Developmental mechanisms that generate precise patterns of neuronal connectivity. Cell 72:77-98.

Grunwald DJ, Kimmel CB, Westerfield M, Walker C, Streisinger G (1988) A neural degeneration mutation that spares primary neurons in the zebrafish. Dev Biol 126:115-128.

Halpern ME, Ho RK, Walker C, Kimmel CB (1993) Induction of muscle pioneers and floor plate is distinguished by the zebrafish no tail mutation. Cell 75:99-111.

Hanneman E, Westerfield M (1989) Early expression of acetylcholines- 
terase activity in functionally distinct neurons of the zebrafish. J Comp Neurol 284:350-361.

Hanneman E, Trevarrow B, Metcalfe WK, Kimmel CB, Westerfield M (1988) Segmental pattern of development of the hindbrain and spinal cord of the zebrafish embryo. Development 103:49-58.

Hatta K, Bremiller R, Westerfield M, Kimmel CB (1991a) Diversity of expression of engrailed-like antigens in zebrafish. Development 112:821-832.

Hatta K, Kimmel CB, Ho RK, Walker C (1991b) The cyclops mutation blocks specification of the floor plate of the zebrafish central nervous system. Nature 350:339-341.

Hume RI, Role LW, Fischbach GD (1983) Acetylcholine release from growth cones detected with patches of acetylcholine receptor-rich membranes. Nature 305:632-634.

Jellies J (1990) Muscle assembly in simple systems. Trends Neurosci 13:126-131.

Kater SB, Rehder V (1995) The sensory-motor role of growth cone filopodia. Curr Opin Neurobiol 5:68-74.

Kelly AM, Zacks SI (1969) The fine structure of motor endplate morphogenesis. J Cell Biol 42:154-169.

Kennedy TE, Tessier-Lavigne M (1995) Guidance and induction of branch formation in developing axons by target-derived diffusible factors. Curr Opin Neurobiol 5:83-90.

Kennedy TE, Serafini T, de la Torre JR, Tessier-Lavigne M (1994) Netrins are diffusible chemotropic factors for commissural axons in the embryonic spinal cord. Cell 78:425-435.

Keynes RJ, Cook GM (1995) Repulsive and inhibitory signals. Curr Opin Neurobiol 5:75-82.

Kimmel CB, Ballard WW, Kimmel SR, Ullmann B, Schilling TF (1995) Stages of embryonic development of the zebrafish. Dev Dyn 203:253-310.

Lance-Jones C, Dias M (1991) The influence of presumptive limb connective tissue on motoneuron axon guidance. Dev Biol 143:93-110.

Lance-Jones C, Landmesser L (1981) Pathway selection by chick lumbosacral motoneurons during normal development. Proc R Soc Lond [Biol] 214:1-18.

Landmesser L (1992) Growth cone guidance in the avian limb: a search for cellular and molecular mechanisms. In: The nerve growth cone (Letourneau P, Kater SB, Macagno ER, eds) pp 373-385. New York: Raven.

Liu DW, Westerfield M (1990) The formation of terminal fields in the absence of competitive interactions among primary motoneurons in the zebrafish. J Neurosci 10:3947-3959.

Liu DW, Westerfield M (1992) Clustering of muscle acetylcholine receptors requires motoneurons in live embryos, but not in cell culture. J Neurosci 12:1859-1866.

Melançon E (1994) The role of muscle pioneers in pathfinding of primary motoneurons in the embryonic zebrafish. Master's thesis, University of Oregon.

Morin-Kensicki EM, Eisen JS (1997) Sclerotome development and peripheral nervous system segmentation in the embryonic zebrafish. Development 124:159-167.

Myers PZ, Bastiani MJ (1991) NeuroVideo: a program for capturing and processing time-lapse video. Comput Methods Programs Biomed 34:27-33.

Myers PZ, Eisen JS, Westerfield M (1986) Development and axonal outgrowth of identified motoneurons in the zebrafish. J Neurosci 6:2278-2289.
Palka J, Whitlock KE, Murray MA (1992) Guidepost cells. Curr Opin Neurobiol 2:48-54.

Patel NH, Martin Blanco E, Coleman KG, Poole SJ, Ellis MC, Kornberg TB, Goodman CS (1989) Expression of engrailed proteins in arthropods, annelids, and chordates. Cell 58:955-968.

Pike SH, Eisen JS (1990) Identified primary motoneurons in embryonic zebrafish select appropriate pathways in the absence of other primary motoneurons. J Neurosci 10:44-49.

Pike SH, Melançon EF, Eisen JS (1992) Pathfinding by zebrafish motoneurons in the absence of normal pioneer axons. Development 114:825-831.

Raible DW, Wood A, Hodsdon W, Henion PD, Weston JA, Eisen JS (1992) Segregation and early dispersal of neural crest cells in the embryonic zebrafish. Dev Dyn 195:29-42.

Schabtach E, Parkening TA (1974) A method for sequential high resolution light and electron microscopy of selected areas of the same material. J Cell Biol 61:261-264.

Sepich DS, Westerfield M (1993) Molecular characterization of zebrafish acetylcholine receptor mutation, nic1. Soc Neurosci Abstr 19:1294.

Serafini T, Kennedy TE, Galko MJ, Mirzayan C, Jessell TM, TessierLavigne M (1994) The netrins define a family of axon outgrowthpromoting proteins homologous to C. elegans UNC-6. Cell 78:409-424.

Sretavan DW, Pur'e E, Siegel MW, Reichardt LF (1995) Disruption of retinal axon ingrowth by ablation of embryonic mouse optic chiasm neurons. Science 269:98-101.

Sun YA, Poo MM (1985) Non-quantal release of acetylcholine at a developing neuromuscular synapse in culture. J Neurosci 5:634-642.

Thisse C, Thisse B, Schilling TF, Postlethwait JH (1993) Structure of the zebrafish snail1 gene and its expression in wild-type, spadetail and no tail mutant embryos. Development 119:1203-1215.

Tosney KW, Landmesser LT (1985a) Development of the major pathways for neurite outgrowth in the chick hindlimb. Dev Biol 109:193-214.

Tosney KW, Landmesser LT (1985b) Specificity of early motoneuron growth cone outgrowth in the chick embryo. J Neurosci 5:2336-2344.

Trevarrow B, Marks DL, Kimmel CB (1990) Organization of hindbrain segments in the zebrafish embryo. Neuron 4:669-679.

van Raamsdonk W, van der Stelt A, Diegenbach PC, van de Berg W, de Bruyn H, van Dijk J, Mijzen P (1974) Differentiation of the musculature of the teleost Brachydanio rerio I. Myotome shape and movements in the embryo. Z Anat Entwicklungsgesch 145:321-342.

Waterman RE (1969) Development of the lateral musculature in the teleost, Brachydanio rerio: a fine structural study. Am J Anat 125:457-493.

Westerfield M (1995) The zebrafish book. Eugene, OR: University of Oregon Press.

Westerfield M, McMurray J, Eisen JS (1986) Identified motoneurons and their innervation of axial muscles in the zebrafish. J Neurosci 6:2267-2277.

Westerfield M, Liu DW, Kimmel CB, Walker C (1990) Pathfinding and synapse formation in a zebrafish mutant lacking functional acetylcholine receptors. Neuron 4:867-874.

Young SH, Poo MM (1983) Spontaneous release of transmitter from growth cones of embryonic neurones. Nature 305:634-637. 